\title{
The Future of Technology and Jobs
}

\author{
An Interview with Dr. R.A. Mashelkar
}

by Arun Kumar Tripathi

\section{Editor's Introduction}

Dr. Raghunath Anant Mashelkar is a National Research Professor and is currently the President of Global Research Alliance. He previously held the positions of Director General of the Council of Scientific and Industrial Research (CSIR) (1995-2006) and President of Indian National Science Academy (2005-2007).

Dr. Mashelkar's groundbreaking research in polymer science and engineering has won him many international laurels. He is a Fellow of Royal Society (FRS), Foreign Associate of the U.S. National Academy of Science and U.S. National Academy of Engineering, Foreign Member, American Academy of Arts \& Sciences, Fellow of Royal Academy of Engineering, U.K., and Foreign Fellow of Australian Technological Science and Engineering Academy.

As Director of National Chemical Laboratory (NCL) between 1989 and 1995, Mashelkar gave a new orientation to NCL's research programmes with strong emphasis on globally competitive technologies and international patenting. This was done even before India liberalized and opened up in 1991. Dr. Mashelkar created a polymer science and engineering division from scratch in NCL that is rated as world class today.

As Director General of CSIR (which is the largest chain of industrial $R$ \& $D$ labs), Dr. Mashelkar conceived and successfully led the process of transformation of CSIR. His white paper "CSIR 2001: Vision \& Strategy" set up a new agenda. Dr. Mashelkar has been a member of the Science Advisory Council to the Indian Prime Minister (SAC-PM) for more than three decades. Deeply connected with the innovation movement in India, Dr. Mashelkar is the Chairman of India's National Innovation Foundation, Reliance Innovation Council, Marico Innovation Foundation, and KPIT Technologies Innovation Council.

Dr. Mashelkar wrote an engaging book, Reinventing India (2011), showing a path to reinvent India [1]. Nobel Laureate Venkataraman Ramakrishnan has this to say about the book '..... it is refreshing to read these essays full of optimism and thoughtful ideas of how India can progress.....'

Nobel Laureate Jean-Marie Lehn has called Dr. Mashelkar “.... A most penetrating observer, broad range actor and a visionary promoter of science, technology and innovation in India." 
The President of India has honored Dr. Mashelkar with the highest civilian honors, namely Padmashri (1991), Padmabhushan (2000), and Padmavibhushan (2014).

The following interview with Dr. Mashelkar is on the prospects of how will technology change the face of employment in the future? What will the jobs of the future look like? What skills are needed to prepare students and researchers for employment in the digital age? As our world is getting digitized day-by-day, technology influences how students communicate, learn, work and interact with society as a whole more than any generation before. Ultimately, students nowadays have to compete with a more globalized, mobile work force, and rapid technological advancement.

Arun Kumar Tripathi

Associate Editor 


\title{
The Future of Technology and Jobs
}

\author{
An Interview with Dr. R.A. Mashelkar \\ by Arun Kumar Tripathi
}

Arun Kumar Tripathi: Is widening computerized automation of knowledge work killing jobs faster than it is creating jobs?

Raghunath Anant Mashelkar: Technology led jobless growth is increasingly a topic of intense discussion around the world, in fact in both the developing and the developed world. Deductions on the basis of current jobs data as also projections for the future are common place.

In their 2013 paper "The Future of Employment: How susceptible are jobs to computerization," Carl Benedikt Frey and Michael Osborne of Oxford University predicted jobs are at high risk of being automated in the U.S. in 47 percent of the occupational categories into which work is customarily divided

What are the factors at work? To my mind, there are three First, some technologies automate physical tasks that human beings used to carry out-from typists to bank tellers, to switch board operators, to typographers. Second, some other technologies can do the intellectual tasks. These include cognitive computing, automation of knowledge work, artificial intelligence, etc. Third, the customer service tasks are also vanishing as new technologies make it possible to create self-help kiosks, or even grocery store scanners.

AKT: But is it not true that technology led productivity will lead to economic growth and that will create jobs rather than just destroy jobs?

RAM: You are right. Automation destroys jobs but it increases productivity. This, in turn leads to economic growth. This creates new jobs. More specifically, productivity and cost gains that are achieved through automation help people to have access to products and services at lower costs, which leads to an increase in consumer savings as well as spending. And all this naturally results in more opportunities for employment in the consumer goods market. So this is one example of automation led productivity led economic growth led jobs! 
AKT: Interesting! When was the term "technological unemployment" first used?

RAM: It was John Maynard Keynes in 1930 who used this term for the first time. He said, "We are being afflicted with a new disease ... technological unemployment." But he ended with an optimistic statement, "But this is only a temporary phase of maladjustment." Perhaps by "maladjustment" he meant the time the society and the economy take to adjust to greater levels of productivity. History shows that his finishing statement has proved to be right again and again. In 250 years since the industrial revolution began, there have been continued, and sometimes very large job losses, by automation. But more jobs continued to be created and unemployment has continued to remain in single digits.

AKT: Should we not, incidentally, be speaking about not just "technology-led growth" but "growth of technology" itself? Should not that mean that technology jobs themselves will increase?

RAM: Yes, you are again right. First, people create technology. However, technology obsoletes itself at an increasingly accelerated pace. Therefore, we need more people, who will create new technology. Further, people are required to maintain any new emerging technology, be it internet of things or advanced robotics or automation of knowledge work or 3-D printing. Then people are also required to assist other people in using new technology. Finally new technology requires new labour forms. Therefore, there will be a great demand for experts to design, test, implement, and refine smart automated information systems. All this means generating more jobs in the future and not less. What changes though, is the nature of jobs.

AKT: Let's take any single category of jobs. Will some technologies increase the jobs in that category and other technologies will work exactly in the opposite direction that means one is creating jobs and other simultaneously destroying jobs?

RAM: This is true. Look at the jobs only in the driver's category. Uber is creating jobs for more drivers. By using technology to create a convenient and efficient reservation and payment service, Uber has created a new market, where customers seek access to cars rather than ownership of cars. Uber has expanded the demand for drivers-who, with the aid of a smartphone and a smart app, can now serve greater number of customers than they might have when they were working for a conventional taxi service. 
On the other hand autonomous vehicles will destroy the jobs for the drivers. A study puts the total estimate of job losses due to autonomous vehicles at 10 million jobs in the next 10-15 years.

But it is not the jobs for drivers alone, other jobs will also get affected because of these technology and business model innovations. Indeed, driverless cars can have a domino effect on a range of jobs in ancillary industries such as the automobile insurance market, automotive finance market, parking industry, and the automotive aftermarket with a suppressed demand for these services and therefore reduced jobs!

\section{AKT: Now let us look at the developing and the developed world. Do you think the two will be affected quite differently?}

RAM: As I had replied to the very first question, analysis by the Martin School in 2013 concluded that 47 percent of U.S. jobs were at risk of automation over the coming two decades. However, their 2016 follow-up report ("Technology At Work v2.0") suggests that the impact will be far greater in the developing world than in the developed world. For instance, the report concludes that 69 percent of jobs in India and 77 percent in China are at "high risk" of automation above the 47 percent figure they found in the U.S. and 57 percent across the OECD.

So far the lower-income countries have enjoyed an advantage of low costs in agriculture and manufacturing. But the above report shows that this advantage will vanish in more and more sectors as robots with advanced automation will replace normal labor. Indeed, with dwindling costs of advanced robots coupled with rising costs of labor in emerging economies, the field will start leveling up. In that case, the legitimate question that will be asked will be what's the difference when a car is manufactured in Detroit or manufactured in a city in India or Vietnam? Not only that, further disruptive technologies, such as 3-D printing, will drive companies to bring their manufacturing back to their home countries.

However, I must also add that there is going to be some time lag, before developing countries will get affected. For example, India is presently a largely informal economy with high transaction costs, and massive exclusion of vast parts of the population from any structured access to goods and services. Therefore, using technology to reduce transaction costs, reducing the informal systems and creating formal systems, and using data to bring consumers and small business into organized credit will create enough productivity and jobs for some years to come. But this will differ in different sectors. There are some sectors (e.g. banking) that are already getting affected very fast. 
AKT: You talked about automation destroying jobs but increasing productivity. Is there any concrete evidence that the growth in productivity will outstrip the job creation?

RAM: We have new learnings on this subject from some eminent scholars. Professors Erik Brynjolfsson and Andrew McAfee from MIT have written a book titled The Second Machine Age: Work, Progress, and Prosperity in a Time of Brilliant Technologies (2014). They predict intelligent machines will increasingly displace many workers but that work will eventually shift to new jobs that technology creates. So the workers will be displaced, not replaced.

Brynjolfsson and McAfee showed, in an interesting graph, separate lines representing productivity and total employment in the United States. For years after World War II, the two lines closely tracked each other, with increases in jobs corresponding to increases in productivity. As I implied earlier in my answers, as businesses generated more value from their workers, the country as a whole became richer, which fueled more economic activity and created even more jobs. These authors very interestingly showed that beginning in 2000 , the lines diverged; productivity continued to rise robustly, but employment suddenly started dropping. By 2011, a significant gap appeared between the two lines, showing growth in economy but no growth in jobs! Brynjolfsson and McAfee call it the "great decoupling." And they felt that technology was behind both the healthy growth in productivity and the weak growth in jobs.

But here is something that counters this hypothesis. In 2011 itself, when Brynjolfsson and McAfee showed that healthy growth in productivity will be complied with week growth in jobs, exactly the opposite happened! As the annual reports of U.S. Bureau of Labor Statistics show, unemployment was 9 percent in the USA in 2011, dropped to 6 percent in 2014, and in 2015 it further dropped to 5 percent. Isn't it interesting?

\section{AKT: What do you think must be responsible for this?}

RAM: Alan Finkel, the new chief scientist of Australia, is one of the most insightful thought leaders in the world. Let me just quote him from an address he delivered for the Melbourne Club KK Club Dinner Speech on November 17, 2014. I do this, because, to me, that quote provides the answer.

Alan had said, "I was given a briefing about the business model of a new Melbourne company named Sonoa Health. They are using smartphone apps, computer applications and an expert systems backend to make it incredibly easy for individuals to learn about health issues, track their own health metrics and create an individualized preventative health plan. You'd think 
Sonoa Health's goal is to bypass traditional GPs, thereby making them obsolete. To the contrary, at the end of the day, all that Sonoa Health can do is alert you to visit your GP for a colonoscopy or to consult her for a check-up or a possible need for treatment. The end result might actually be an increase in the number of GP visits."

In other words, there is an innovation led growth (often unanticipated) that is responsible for this phenomenon. New theoretical frameworks will be needed to deal with such aspects of job growth that Alan Finkel refers to in the aforementioned Melbourne Club speech.

\section{AKT: But what about jobs that require high level of human intellect, intuition, emotion, etc.?}

RAM: Jobs that require emotional and relational work, creativity, synthesizing, problem-solving, and intelligent interpretation will still continue to require human intervention, but that itself is reducing.

Exponential growth of computing power is leading to a superlative increase in artificial intelligence. We already see Google Translate displacing translators, investment advice algorithms displacing investment advisors, automated landing systems replacing airplane piloting skills, and so forth.

Advances in user interfaces, such as speech and gesture recognition technology, are giving computers the ability to respond directly to human commands and requests. For instance, Apple's Siri and Google Now use such natural user interfaces to recognize spoken words, interpret their meanings, and act on those meanings.

Indeed the advances in natural language processing have led to the creation of intelligent interactive voice response systems. These are replacing traditional call centers and manual agents. This means higher efficiency and lower costs of operation. IPSoft claims its cognitive agent Amelia can work along with human call center agents and is able to learn and understand like a human.

The field of radiology is such that it requires several years of hard work to achieve mastery. But now, systems such as the ones made by BD FocalPoint can interpret medical images and look for abnormalities such as tumors with greater speed and accuracy than a human can. Going beyond, oncologists at Memorial Sloan-Kettering Cancer Center in New York are already using IBM's Watson supercomputer to provide chronic care and cancer treatment diagnostics [2]. 
AKT: There will be jobs that require subtle judgments and extraordinarily creative problem solving ability. What about them?

RAM: Computers are increasingly performing tasks that are typically considered "human"such as complex analyses, subtle judgments, and creative problem solving. We will be able to interact with a machine in the way that one would with a coworker. Instant access to information and substantial enhancement in the quality and pace of decision making, and consequently, the performance, will be the benefit.

Advances in software are already giving computers the ability to draw conclusions from patterns they discern within huge data sets. Computers with machine learning capabilities are no longer relying only on fixed algorithms and rules. They are modifying and adjusting their own algorithms based on analyses of data, enabling them to "see" relationships or links that a human mind might overlook. Moreover, these machines are "learning" more and getting smarter day by day.

AKT: Let me come to the continuing challenge of a computer beating a human mind. Has there been any progress after the IBM chess computer Deep Blue beat Grandmaster Gary Kasparov in 1997 ?

RAM: Yes, the best human players of chess, draughts and backgammon have all been outplayed by computers, but we are going beyond this-and fast.

Go, an ancient board game, has been always viewed as one of the greatest challenges for artificial intelligence (Al). But in early October of 2015 even that challenge was overcome. Google's Deep Mind's program AlphaGo beat Fan Hui, the European Go champion, five times out of five in tournament conditions. Most interestingly, it came a decade before anyone expected it!

And then came yet another striking news. In late March 2016, AlphaGo took on and defeated legendary Go player, Lee Sedol, who has won 18 world titles.

What is really remarkable is that AlphaGo played many unprecedented and creative moves. Apparently, According to experts, AlphaGo's move 37 in Game 2 had a one in 10,000 chance being played by a human!

You mentioned Deep Blue beating Gary Kasparov. Deep Blue was explicitly programmed to win the game. But AlphaGo was not preprogrammed this way. It learned using a general purpose algorithm that allowed it to interpret the game's patterns. When beating Fan Hui, it had trained 
on 100,000 existing games, then played about 30 million games against itself to develop new strategies.

May be similar techniques could be applied to other Al domains, which need complex patterns recognition, and decision-making based on long-term planning!

AKT: What about jobs such as book writing, music, acting, movie making that really requires head as well as heart? This will involve empathy, compassion and human emotion on one hand and imagination, intuition and creativity of the highest order at the other end.

RAM: Technology is not sparing any of these. Intelligent machines are influencing book writing. For instance, Scott Finch used software equipped with artificial intelligence. He programmed his Macintosh computer and turned out three quarters of the prose in a potboiler entitled Just This Once.

Musicians are being challenged by the new generation of high-tech synthesizing machines, since they are redefining the way music is made. A synthesizer reduces musical sound to digitized form. Once digitized, the sounds can be stored and be combined with other digitized sounds to create even an entire symphony orchestra. Vince Di Bari, former vice president of the Los Angeles local of the American Federation of Musicians, estimated recording jobs for human musicians have dropped off by at least 35 percent because of synthesizers.

The new technology of "morphing" - which allows movie and television producers to isolate, digitize, and store every visual expression, movement, and sound of an actor and then reprogram them in virtually any new combination-effectively creates new roles and performances for the artist. This isn't something new. Back in the '90s Jeremy Rifkin reported an interesting speculation made by Nick de Martino, who was the head of the American Film Institute [3]. de Martino exlplained how with new computer technologies one could replace sound stages, sets, and even actors with "synthespians," which could be easily "created from libraries of gestures and expressions housed in a computer bank." It might have sounded like a fancy that entertainers could be increasingly competing for parts against their digitized and stored past images, but today technology increasingly has the power to convert that fancy into a reality. 
AKT: But would there be some jobs, where the human will still retain its exclusivity?

RAM: My hope is the following. After all, technology can deal with logic very well. But logic is only one part of the human mind. Inspiration, creativity and intuition, meaning-making, storytelling and communication are all things that humans can do so well that it will be hopefully difficult for computers to make it. And here also I have to say, hopefully!

\section{AKT: What about inequalities in the world? How will they be affected?}

RAM: I will cite two scholars on this subject. Tyler Cowen, a great global thought leader, wrote an outstanding book titled Average is Over: Powering American Beyond the Age of Great Stagnation (2013). It outlines a dual track economic reality wherein those who leverage automation enjoy an escalating standard of living, while those displaced by automation descend into a dramatically reduced standard of living.

In his book, Rise of the Robots: Technology and the Threat of a Jobless Future (2015), Martin Ford states the advent of information technology has replaced workers instead of making them more valuable, leading to increasing income inequalities between workers who possess the skills to adapt to tectonic technological shifts and those who do not.

But I must add that "inclusion" is as important as "inequality," and they will be differently affected and this can be explained easily.

\section{AKT: So can you explain it?}

RAM: Let me take the example of India. The visionary Indian Prime Minister, Narendra Modi, has set the idea of "digital India" in motion. India has one of the lowest PC penetrations in the world, but it has one of the highest mobile phone penetrations, with almost a billion mobile phones across a population of 1.31 billion Indians. With mobile internet becoming affordable and therefore available and accessible to the masses, the possibilities of inclusion become increasingly possible, despite the large income inequality in India.

Take, for instance the idea of "financial inclusion." India's Pradhan Mantri Jan-Dhan Yojana (starting in 2014) has opened up 200 million new bank accounts for the resource poor people in just a few months. In India, the Aadhar Card is a unique identification card that 950 million Indians already have. Couple this with India's one billion mobiles phones providing, hopefully, affordable access to mobile internet. With this "JAM" combination (meaning Jan Dhan Yojna, 
Aadhar Card and Mobile combination), the majority of the excluded Indian population will have financial inclusion. What is true for financial inclusion will become true for inclusion in terms of education, health services, etc.

\section{AKT: Any final word?}

RAM: Going forward, it seems inevitable that the proportion of the population who needs to engage in traditional full-time employment in order to keep humanity fed, supplied, healthy, and safe will decrease. My strong hunch is this will hopefully lead to a humane restructuring of the general social contract around the type and number of jobs and employment in the world, and, again hopefully a better world.

\section{AKT: Thank you very much for the stimulating answers.}

RAM: It was a privilege and an honor.

\section{References}

[1] Mashelkar, Raghunath A. Reinventing India, Sahyadri Prakashan, 2011.

[2] McKenzie Global Institute. Disruptive Technologies: Advances that will Transform Life, Business and Global Economy. May 2013, p.45.

[3] Rifkin, J. "New Technology and End of Jobs." In The Case Against the Global Economy and For a Turn Towards the Local. Jerry Mander and Edward Goldsmith (eds.) Sierra Club Books, 1997.

\footnotetext{
About the Author

Arun Kumar Tripathi is an Independent Scholar in India. Arun is the editorial board member and associate editor of Artificial Intelligence \& Society (Journal of Knowledge, Culture and Communication) Springer, London. From 2004 to 2009 he has worked in-collaboration with Department of Computer Science at TU Dresden on a European Project, "Future of Identity in the Information Society (FIDIS), Network of Excellence." He has been working on the interface
} 
of Mathematics, Computer Science and Philosophy of Technology. For the past 16 years he has been pursuing research on technoscience and the influence of technologies on Western culture and historical consciousness. In the past, he has worked as a Research Assistant (2002-2009) at the Department of Philosophy of Technology, Institute for Philosophy, Dresden University of Technology, Germany. His current research interests emphasize the future prospects of humancomputer interaction, interface of human cognition and technology, trust and experts, impact of science $\&$ technology on society and computers in education.

DOI: $10.1145 / 2903524$ 